\title{
Defining and Measuring Students' Interest in Biology: An Analysis of the Biology Education Literature
}

\author{
Ashley A. Rowland, ${ }^{\dagger}$ Eva Knekta, ${ }^{\ddagger \S}$ Sarah Eddy, ${ }^{\ddagger}$ and Lisa A. Corwin ${ }^{\dagger *}$ \\ ${ }^{\dagger}$ Department of Ecology and Evolutionary Biology, University of Colorado, Boulder, Boulder, \\ CO 80309; :Department of Biological Sciences, Florida International University, Miami, FL 33199; \\ §Department of Science and Mathematics Education, Umeå University, 90187 Umeå, Sweden
}

\begin{abstract}
Understanding how students develop biology interests and the roles interest plays in biology contexts could help instructors and researchers to increase science, technology, engineering, and mathematics students' motivation and persistence. However, it is currently unclear how interest has been defined or measured in the biology education research literature. We analyzed this body of literature to determine how interest has been defined and used by the biology education research community. Specifically, we determined the extent to which previously published work drew on theories that conceptualize interest. Further, we identified studies that measured student interest in biology and characterized the types of measures used. Our findings indicate that biology education researchers typically describe interest as a relationship involving positive feelings between an individual and a physical object, activity, or topic of focus. We also found that interest is often not defined, theories involving interest are not often consulted, and the most common measures of interest only assess a single aspect of the construct. On the basis of these results, we make suggestions for future research seeking to examine biology students' interest. We hope that this analysis can serve as tool for biology educators to improve their own investigations of students' interest and measure outcomes of interest-generating educational activities.
\end{abstract}

\section{INTRODUCTION}

Interest has been valued as a key component of academic achievement for more than a century (Dewey, 1913; Thorndike, 1935). Interest is also considered by many social cognitive psychologists to be an important component of motivation (Ryan and Deci, 2000; Krapp, 2002; Eccles et al., 2015; Renninger and Hidi, 2015), which leads to persistence in science, technology, engineering, and mathematics (STEM; Graham et al., 2013). As such, it has been seen as a vital part of science education as well as biology education specifically (Renninger et al., 2015).

Evidence suggests that biology education, particularly undergraduate biology education, may face a unique challenge when it comes to building students' interest in biology content. Because undergraduate biology courses train students for a wide variety of careers, from medical doctors to conservation biologists to academic or industry researchers, students may be drawn to the subject not because of their interest in biology per se, but because of other peripheral interests or career goals. For example, Pacifici and Thomson (2011) showed that pre-medical school students are motivated more by helping others than by learning science. This suggests a potential lack of interest in biology content and perhaps stronger interests outside the discipline itself (Pacifici and Thomson, 2011). Low disciplinary interest poses a potential threat to motivation (Ryan and Deci, 2000; Renninger, 2000; Renninger and Hidi, 2015; Krapp, 2002; Glynn et al., 2015) and, ultimately, students' persistence in STEM (Graham et al., 2013). Indeed, one of the most commonly cited reasons for leaving a

Cynthia Brame, Monitoring Editor

Submitted Feb 11, 2019; Revised Apr 30, 2019; Accepted May 6, 2019

CBE Life Sci Educ September 1, 2019 18:ar34 DOI:10.1187/cbe.19-02-0037

*Address correspondence to: Lisa A. Corwin (lisa .corwin (acolorado.edu).

(C) 2019 A. A. Rowland et al. CBE-Life Sciences Education ๑ 2019 The American Society for Cell Biology. This article is distributed by The American Society for Cell Biology under license from the author(s). It is available to the public under an Attribution-Noncommercial-Share Alike 3.0 Unported Creative Commons License (http://creativecommons.org/licenses/ by-nc-sa/3.0)

"ASCB®" and "The American Society for Cell Biology ${ }^{\circledR}$ " are registered trademarks of The American Society for Cell Biology. 
STEM major during college is lack of interest in the major itself (Seymour and Hewitt, 1997). Thus, we as biology educators must consider our students' interest in biology as a key factor for their motivation, persistence, and success. Yet the extent to which interest has been considered within the biology education literature is currently unclear.

To better comprehend the role of interest in biology education and understand how interest influences student success, we must first understand how the term has been defined and measured in biology education practice and research. For a term like "interest," which has varied colloquial and theoretical meanings, determining a definition from the literature is not straightforward. As a construct (i.e., an explanatory variable that is not directly observable), interest is complex. Motivational and learning theories have described interest as a multidimensional construct comprising affective (e.g., liking), cognitive (e.g., assigning value, storing knowledge), and behavioral (e.g., reengaging with specific content) components (Schiefele and Csikszentmihalyi, 1994; Krapp, 2002; Renninger and Hidi, 2015). Likewise, the meaning of interest may vary based on the colloquial uses of the term (Valsiner, 1992). Interest is also often confused with engagement, attention, and curiosity (Renninger and Hidi, 2011, 2015), further complicating our understanding. A precise definition of interest is crucial, as it adds clarity to the authors' meaning and intent and informs the measurements used in a research study. Measurement, in turn, affects the results and interpretations that we draw from data, giving rise to the claims we make about interest. These claims ultimately impact our understanding and reinforce our definition. Each step in this process can inform or be informed by theory (Figure 1). Using a vetted theory that aligns with the study's purpose informs the definitions and measures of interest used in research. The use of theory also serves to situate results and claims in a broader understanding of students' psychological and motivational states. However, we currently do not know the extent to which interest studies are theory driven in the biology education research literature. Thus, we investigate what is meant by "interest" in biology education in order to situate our knowledge within the context of existing studies, execute practices aimed at increasing interest in biology, and further elucidate the role interest plays in student success.

Here, we analyzed education research articles that discuss student interest in biology. We aimed to determine 1) whether and how interest was defined in order to form an understand-

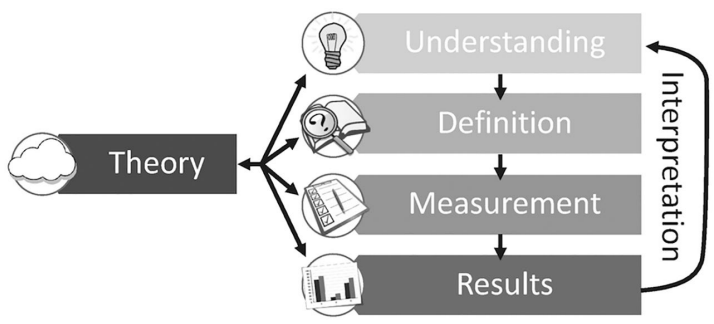

FIGURE 1. Theory impacts several components that contribute to the overall understanding of a construct. A researcher's understanding of the construct will inform how it is defined and the form of measurement selected. Measurements, in turn, impact the results and interpretations that form the overall understanding of the construct. ing of what interest means to the biology education research community, 2) whether interest research in biology education drew from theories of interest or motivation in order to identify the theories that have shaped the field's understanding of the construct, and 3) whether interest was systematically measured in the field of biology education research and what types of measurements were used. Following our investigation of aims $1-3$, we analyzed the common definitions and interest measurements to 4) inductively identify emergent themes that shed light on how interest has been broadly conceptualized by the biology education research community. We hope the results of our analysis will serve to form an understanding of what interest in biology means to the community and improve future interest research within biology classrooms and undergraduate education.

\section{METHODS}

To conduct a thorough analysis of the literature and determine how points 1-4 were addressed, we used a systematic literature review methodology to guide the process (Cacciotti, 2015). This process involved describing research objectives, defining conceptual boundaries, establishing inclusion criteria, and applying exclusion criteria.

\section{Research Objectives of the Literature Analysis}

We described the following research objectives:

1. Determine whether and how interest was defined by the biology education research literature and describe the most commonly referenced definitions.

2. Determine whether past biology education research referenced theories of interest or motivation and describe commonly referenced theories.

3. Determine whether interest was measured systematically when interest was reported and characterize the structures and common topics of measurement.

4. Identify emergent themes and commonalities across commonly used definitions and interest measures.

\section{Defining the Conceptual Boundaries of the Literature Analysis}

Conceptual boundaries define the topic(s) under discussion to limit the scope to relevant foci (Cacciotti, 2015). For this analysis, we investigated the topics "interest" and "biology" within the educational literature.

To fully capture interest as a topic, we relied on the conceptualization of interest selected by the authors of the literature returned in the database search. Valsiner (1992) explains that the word "interest" is embedded in our common language, and as such, interest may be operationally defined less frequently. Terms such as "curiosity," "attitude," "liking," "attention," or "engagement" may be conflated in the literature with "interest," despite having distinct definitions and meanings. Thus, some articles addressing interest may have labeled it with a different term, making it difficult to identify relevant studies to analyze, an issue that others have acknowledged (Schiefele et al., 1992). Although we recognize this limitation, we chose to not include these terms (e.g., "curiosity") in our search in order to carefully consider how biology educators and researchers use the term "interest" specifically. 
By designating biology as a topic, we broadly captured literature from all of the life sciences, including subdisciplines of biology, such as molecular biology, anatomy, and ecology, and hybrid disciplines, such as biochemistry and biotechnology. We did not specify a context for biology education literature and thus included formal and informal learning environments (e.g., classrooms vs. museums) and various ages (K-16). Thus, our conceptual boundaries were broad for both topics, which allowed us to summarize how "interest" is used in the existing biology education literature and capture the many contexts and age groups that have been investigated with respect to building interest in biology, including its many subfields.

\section{Establishing the Inclusion Criteria of the Literature Analysis}

Inclusion criteria consist of 1) search boundaries, which can include literature databases, conference proceedings, and other sources of information; 2) precise search terms; and 3) the period of time covered in the search (Cacciotti, 2015).

To capture literature focused on both biology and education, we performed a literature search using the Education Resources Information Center (ERIC), an online library of education research and information sponsored by the Institute of Education Sciences of the U.S. Department of Education (https://eric .ed.gov). ERIC indexes a wide variety of journal sources, including many prominent science education and biology education journals. Searching ERIC allowed us to target only education research for analysis, which served our purpose of understanding specifically how educators and education researchers conceptualize interest in biology education.

We performed the search of the ERIC database using "descriptor: interests AND descriptor: biology" as the precise search terms. The descriptor "interests" was described in ERIC as activities, avocations, objects, and so on that have special worth or significance for individuals or groups and are given special attention. Related terms identified included activities, affective behavior, attitudes, cognitive structures, interest inventories, interest research, motivation, and participation. The use of the descriptor "biology" narrowed the search results to sources that emphasized the field of biology and encompassed a wide variety of biology subdisciplines (e.g., ecology) and hybrid disciplines (e.g., biochemistry). These search terms in the ERIC database returned 255 sources.

We then chose to limit the search years to when the modern conceptualizations of interest first arose in social cognitive psychology (1988-2018). While interest was first considered important for motivation in an educational context in the early 1900s (Dewey, 1913; Thorndike, 1935), it was not until the late 1980s and early 1990s that interest was conceptualized and incorporated into larger theories of motivation. In 1986, Hidi and Baird examined situational interest, first suggesting that there were two stages, triggered interest and maintained interest (Hidi and Baird, 1986). Then, in 1990, Hidi described situational interest as an affective reaction that may not last and is generated by particular conditions and/or objects in the environment that focus attention (Hidi, 1990). The conceptualization of individual interest has evolved over time to describe the relationship between a person and a particular subject area or object. The distinction between situational and individual interest was first suggested by Hidi (1990), and evidence for the distinction was made clear by Renninger (2000). Because an explicit definition of interest arose and was available for reference by the biology education literature in the late 1980s and early 1990s, literature from the past 30 years (1988-2018) was selected for analysis. In addition to the availability of a clear definition, evidence began accumulating in the 1990s that empirically demonstrated the critical role that interest plays in student motivation. Of the 255 articles returned in the search, 200 were published during the time period from 1988 to 2018 .

\section{Applying Exclusion Criteria to the Literature Analysis}

Exclusion criteria for a literature analysis describe the filters used to determine whether literature returned in the search is relevant to the research objectives (Cacciotti, 2015). Here, our exclusion criteria ensured that sources identified in the search were related to both biology education and student interest.

First, as described earlier, papers were excluded from the analysis if they were published before 1988. Furthermore, papers and other materials were excluded if they were not vetted by members of the field through peer review. For example, materials published by an organization, dissertations, or conference proceedings were not included. The initial inclusion and exclusion criteria returned 177 sources (Table 1).

To ensure that the literature returned in the search was relevant to our investigation, we excluded papers if they were not specifically related to students' interest in a biology education context. Thus, we excluded sources that measured variables outside student educational contexts, such as Dunkerton's (2007) study that explored how teachers' confidence in teaching techniques influenced their exploration of biology outside the classroom. We also excluded papers that mentioned students' interests more generally, but not in biology content specifically, and instead refer to biological characteristics of students as predictors of various interests. For example, Hansen et al. (2011) predicted students' interests broadly speaking based on neurobiological studies. We included biology education in informal contexts such as museums or after-school programs and formal contexts such as classrooms or lectures, because both contexts involve biology learning and can tell us about how the biology education community views interest. Of the 177 peer-reviewed, post-1987 papers, 161 were determined to be related to biology education content (Table 1).

Finally, to ensure that the literature returned in the search was relevant to our analysis with respect to students' interest, we excluded papers if they did not either 1) emphasize the importance of interest within the manuscript and/or 2) report

TABLE 1. Applying exclusion criteria to identified literature limits analysis to relevant articles

\begin{tabular}{lc}
\hline Criterion & Number \\
\hline Total articles identified in search & 255 \\
Published 1988-2018 (of 255) & 200 \\
Peer reviewed (of 200) & 177 \\
Related to biology education content (of 177) & 161 \\
Either: & \\
$\quad$ Emphasizes the importance of interest (of 161) & 125 \\
and/or: & 109 \\
$\quad$ Reports on students' interest (of 161) & 139 \\
Final relevant articles analyzed in the review &
\end{tabular}


TABLE 2. Analysis of relevant literature for interest definitions, theories, and measurements

\begin{tabular}{lc}
\hline Criterion & Number (\%) \\
\hline Defined or cited a definition of interest (of 139) & $36(26)$ \\
Referenced a theory involving interest (of 139) & $51(37)$ \\
Systematically measured interest (of 139) & $93(67)$ \\
\hline
\end{tabular}

on student interest in biology, including students' existing interests, intensity of interest, or changes in interest. This often excluded articles that were purely lesson plans, which emphasized the classroom activities rather than interest and made only peripheral comments regarding interest. Of the 161 papers relevant to biology education, 125 emphasized interest, and 109 reported on student interest, including topics of interest to students, interest intensity, or changes in interest (Table 1). Note that there is overlap in papers across these two categories, because some papers both emphasized interest and reported on students' interest in biology, resulting in a total of 139 analyzed articles.

\section{Analysis of Identified Relevant Literature}

Our identification strategy resulted in an analysis of 139 empirical articles that concerned students' interest in biology (see
Appendix 1 in the Supplemental Material for a list of analyzed literature). We created a catalogue containing citation information for each article to facilitate our analysis and address the four research objectives.

First, to identify definitions of interest, we searched each paper for instances of the word "interest" (Table 2). Each time the word "interest" appeared, two authors (A.A.R. and E.K.) read the surrounding sentence or paragraph for context and to identify definitions. For example, definitions frequently appeared in the context of "Interest is..." or "Interest has been defined as..." The sentences containing the definition and the citation referenced in the paper, when present, were copied into the catalogue of articles. The definitions were then further analyzed and classified into groups based on similarity and origin (Table 3 and Supplemental Table 1).

Second, we analyzed each paper to catalogue the mention of theory(ies) focused on interest or motivation (Table 2). Two authors (A.A.R. and E.K.) with expertise in interest theories read the introductory and theoretical framework sections of the publications in addition to paragraphs containing the word "interest" to identify mentions of theory. These authors applied their expertise to recognize and categorize references and passages that referred to specific theories. Unfamiliar references were examined to determine whether they were

TABLE 3. Commonly referenced definitions of interest in the biology education literature

\begin{tabular}{lc}
$\begin{array}{l}\text { Number of } \\
\text { papers citing }\end{array}$ & \multicolumn{1}{c}{ Foundational publication } \\
\hline 21 & Hidi, S., and Renninger, K. A. (2006). \\
& The four-phase model of interest \\
& development. Educational \\
& Psychologist, 41(2), 111-127. \\
& doi:10.1207/s15326985ep4102_4 \\
& \\
& \\
& \\
& Schiefele, U. (1991). Interest, \\
& learning, and motivation. \\
& Educational Psychologist, 26(3-4), \\
& 299-323. doi:10.1080/00461520. \\
& 1991.9653136
\end{tabular}

Gardner, P. L., and Tamir, P. (1989). Interest in biology. Part I: A multidimensional construct. Journal of Research in Science Teaching, 26(5), 409-423. doi:10.1002/tea.3660260506

Ryan, R. M., and Deci, E. L. (2000). Self-determination theory and the facilitation of intrinsic motivation, social development, and well-being. American Psychologist, 55(1), 68-78. doi:10.1037/0003066X.55.1.68

Csikszentmihalyi, M., and Hemanson, K. (1995). Intrinsic motivation in museums: Why does one want to learn? Public Institutions for Personal Learning, 74(34), 67-75.
Definition of interest

Interest is described most simply as a relationship between a person and an object. Interest comprises both cognitive and affective dimensions.

Interest exists in two forms: situational and individual.

Situational interest is external and appears suddenly as a response to something in the environment.

Individual interest is internal and stable. It develops gradually and becomes a long-lasting preference for a topic that is also described as an enduring predisposition to reengage with particular content.

"Individual interest is interpreted here as the relatively long-term orientation of an individual toward a type of object, an activity, or an area of knowledge" (p. 302). It consists of three valences: 1) a feeling-related valence, which refers to the feelings that are associated with a topic or an object; 2) a value-related valence, which refers to the attribution of personal significance to an object; and 3) intrinsic character, which means that the person is involved in a topic for its own sake and not for any external reason.

Interest may be regarded as a predisposition or trait, and it can also be regarded as an emotional feeling or state. "The term 'interest' usually refers to a preference to engage in some types of activities rather than others. An interest may be regarded as a highly specific type of attitude: When we are interested in a particular phenomenon or activity, we are favorably inclined to attend to it and give time to it" (p. 410).

Interest is a form of "intrinsic motivation" and a core affect of the self, which refers to doing something because it is inherently interesting or enjoyable. Intrinsic motivation is seen when a person displays a behavior because of internal emotions, such as pleasure or interest.

Interest refers to a differential likelihood of investing energy in one set of stimuli rather than another. The experience of being interested has been characterized as an optimal state that combines positive affective qualities (e.g., feelings of immediate enjoyment, good moods, etc.) and positive cognitive qualities (e.g., striving for meaningful goals, relevance, etc.). 
related to a theory. When present, we copied the implicitly or explicitly referenced theories and citations into the catalogue mentioned earlier. As with the catalogued definitions of interest, we analyzed the theories for shared origin and further classified papers referencing theory into groups (Table 4 and Supplemental Table 2).

Third, two authors (A.A.R. and E.K.) determined whether interest was systematically measured (Table 2). We defined systematic interest measurement as a methodical approach in which the authors planned to employ a tool to measure interest at a specific time and place for a specific population and reported on the data gathered. Our definition of a systematic measurement was inclusive and did not take into account the quality of the measurement since we wanted to analyze every paper that measured interest. Also, we interpret the term "measure" broadly to include both qualitative and quantitative means of data collection. To identify systematic interest measures, we analyzed the methods and results sections of each paper and identified items or methods that the researcher described as being indicative of interest. We looked for the application of a single question or series of questions in the form of either a questionnaire or an interview protocol that targeted interest. We also included regular, planned observations of participants' behaviors or interactions as interest measures if they explicitly targeted interest. Examples of nonsystematic interest measurement included publications that reported changes in interest as a result of some educational program, but in which interest measurement was not initially planned or intentionally executed. In many of these papers, interest was anecdotally reported as a result of informal observations. We excluded these instances from our measurement analysis as well as those that reported interest as an inductively identified theme in an exploratory or ethnographic study rather than as a targeted objective of the study. Instances of systematic interest measurement were recorded in the catalogue, as were the items measuring interest when present.

Next, we examined the catalogued measures and inductively classified them by type, which gave rise to three initial categories: 1) measures collecting qualitative data, including openended written-response questions, student works (e.g., essays), interviews, and observations; 2) measures collecting quantitative data, including multiple-choice items, and Likert-type items (i.e., any question that generated numeric data as opposed to text, observations, or audio data); and 3) measures that used mixed methods to collect both qualitative and quantitative data (Table 5). We then further classified the quantitative measures based the origin of measurement, measurement structure, and specific aspects addressed (e.g., positive affect) (Tables 5-7). To determine the origin of the measurement, we examined whether the measure was 1) author developed, including instances when an author completely developed the questionnaire from scratch, questionnaire items were assembled from several different existing questionnaires, or major changes were made to an existing questionnaire; or 2) an existing measurement published elsewhere, including instances when minor adaptations were made (e.g., changing the word "physics" to "biology"; Table 5). We then inductively identified five types of interest measures, including single item, single aspect, multi-aspect, multidimensional scale, and unknown (see Results and Table 6 for complete descriptions of each category). Because the single-item and sin- gle-aspect measures examined only one aspect (defined as a single specific component of a construct), we further classified them by the type of items they used. We classified single-item and single-aspect measures into three categories: interestfocused measures, affect-focused measures, and measures that probe students' desire to learn (Table 7). Supplemental Table 3 contains complete information on how the 93 papers that contained quantitative measures were classified.

Overall, the catalogue of analyzed literature grew into a detailed archive of the relevant literature that we then mined for trends and commonalties in interest conceptualization. For our final step in the analysis, two authors (A.A.R. and L.A.C.) examined the analyzed set of definitions and measurements to inductively identify emergent themes that shed light on how biology education researchers understood interest as a concept (i.e., their conceptualization of interest). These authors described and reached consensus on only those themes that were present in both the definitions and measurements sections of analyzed literature. We chose this criterion because the definitions and measures reflect the understanding of the biology education research community regarding interest (Figure 1). After theme identification, A.A.R. and L.A.C. conferred with E.K., and S.E. to confirm theme presence, which constituted a second check on theme identification. We then made final adjustments to theme descriptions.

\section{RESULTS}

To address our core research objectives, we analyzed each of the relevant sources identified in our search to determine whether they 1) offered a precise definition of interest or cited another source's definition of interest, 2) referenced any theory(ies) of interest or motivation, and 3) measured interest. Finally, we examined our analyzed results regarding definitions and measures and 4) characterized broad themes spanning the literature.

\section{Approximately One-Fourth of Papers That Reported or Emphasized Interest Provided a Definition of Interest}

Of the 139 articles that reported interest or emphasized the importance of interest in the biology education literature, $36(26 \%)$ offered a definition of interest (Table 2). Table 3 paraphrases the definitions of interest referenced in the literature and notes the foundational publications (publications that describe the referenced definition in detail). Many of the commonly referenced definitions cite authors who have contributed significantly to the conceptualization of interest and to theories of interest development and motivation, described in the next section. Interest also had different meanings and played different roles in the biology education literature depending on the definition cited. For example, Ryan and Deci's (2000) conceptualization focuses primarily on whether a task is enjoyable, while Schiefele (1991) describes multiple dimensions of interest, including enjoyment and value. These definitions inform the claims that can be made based on different studies. Several papers analyzed mentioned more than one definition of interest and cited multiple authors. Thus, a single paper might be tallied for more than one definition in Table 3. Specific papers that reference each definition are detailed in Supplemental Table 1. 
TABLE 4. Commonly referenced theories relating to interest in the biology education literature

\begin{tabular}{|c|c|c|}
\hline $\begin{array}{l}\text { Number of } \\
\text { papers } \\
\text { citing }\end{array}$ & Name of theory & Foundational publication \\
\hline 23 & $\begin{array}{l}\text { The four-phase } \\
\text { model of interest } \\
\text { development }\end{array}$ & $\begin{array}{l}\text { Hidi, S., and Renninger, K. A. } \\
\text { (2006). The four-phase model of } \\
\text { interest development. Educa- } \\
\text { tional Psychologist, } 41(2), \\
\text { 111-127. doi:10.1207/ } \\
\text { s15326985ep4102_4 }\end{array}$ \\
\hline 20 & $\begin{array}{l}\text { Person-object } \\
\text { approach to } \\
\text { interest }\end{array}$ & $\begin{array}{l}\text { Krapp, A. (1993). Characteristics of } \\
\text { individual interests and } \\
\text { interest-related actions from the } \\
\text { perspective of a person-object } \\
\text { theory. Studies in Educational } \\
\text { Psychology, 4(January), 297-329. } \\
\text { doi:10.17559/ } \\
\text { TV-20150807194942 }\end{array}$ \\
\hline 17 & $\begin{array}{l}\text { Self-determination } \\
\text { theory }\end{array}$ & $\begin{array}{l}\text { Ryan, R. M., and Deci, E. L. (2000). } \\
\text { Self-determination theory and } \\
\text { the facilitation of intrinsic } \\
\text { motivation, social development, } \\
\text { and well-being. American } \\
\text { Psychologist, 55(1), 68-78. } \\
\text { doi:10.1037/0003-066X.55.1.68 }\end{array}$ \\
\hline
\end{tabular}

Schiefele, U. (1991). Interest, learning, and motivation. Educational Psychologist, 26(3-4), 299-323. doi:10.1080/ 00461520.1991 .9653136 Expectancy-value
theory
Wigfield, A., and Eccles, J. S. (2000). Expectancy-value theory of achievement motivation. Contemporary Educational Psychology, 25(1), 68-81. doi:10.1006/ceps.1999.1015
Description of the theory and role of interest

The four-phase model describes how interest develops in an individual over time. The four phases are 1) triggered situational interest, 2) maintained situational interest, 3) emerging individual interest, and 4) well-developed individual interest. In phases 1 and 2, interest is a psychological state that results from short-term changes in cognitive and affective processing associated with a particular class of content. In the later phases, interest is both a psychological state and a relatively enduring predisposition to reengage a particular class of content over time.

The person-object approach to interest is a theoretical framework that describes interest as a specific relationship between a person and an object. According to this framework, interest can be investigated at the level of a person's experience and behavior related to the object of interest (action of interest) and at the level of habitual or dispositional factors of personality associated with the object of interest (personal interests).

Self-determination theory is a theory of motivation that defines intrinsic and varied extrinsic sources of motivation. Competence, relatedness, and autonomy are argued to be three components that are essential for facilitating an individual's optimal growth and social integration, as well as for constructive social development and personal well-being. Interest is a form of "intrinsic motivation" which is key to a subtheory of selfdetermination theory, called cognitive evaluation theory. Cognitive evaluation theory is based on the idea that people are intrinsically motivated only for activities that hold intrinsic interest for them, activities that have the appeal of novelty, challenge, and aesthetic value.

Valence beliefs describe interest as a multidimensional construct that is specific to the content. As described in Table 3, "individual interest is interpreted here as the relatively long-term orientation of an individual toward a type of object, an activity, or an area of knowledge." It consists of three valences: 1) a feeling-related valence, which refers to the feelings that are associated with a topic or an object, 2) a value-related valence, which refers to the attribution of personal significance to an object, and 3) intrinsic character, which means that the person is involved in a topic for its own sake and not for any external reason.

Expectancy-value theory is a theory of achievement motivation that seeks to explain people's choice to engage in tasks, persistence on those tasks, vigor in carrying them out, and performance on them. The essential components of the theory are expectancies for success and values. Expectancies for success are the individual's belief that he or she can accomplish a task. There are four major dimensions of value: 1 ) attainment value- the importance of doing well on a given task, 2) intrinsic value-the enjoyment one gains from doing the task, 3) utility value-how a task fits into an individual's future plans, and 4) costs-the perceived drawbacks of engaging in a task (e.g., effort, limiting engagement in other activities, and emotional toll). In this theory, intrinsic value is synonymous with interest and concerns doing a task out of enjoyment. 
TABLE 4. Continued

\begin{tabular}{|c|c|c|c|}
\hline $\begin{array}{l}\text { Number of } \\
\text { papers } \\
\text { citing }\end{array}$ & Name of theory & Foundational publication & Description of the theory and role of interest \\
\hline 2 & Flow theory & $\begin{array}{l}\text { Davis, M. S., and Csikszentmihalyi, } \\
\text { M. (1977). Beyond boredom and } \\
\text { anxiety: The experience of play } \\
\text { in work and games. Contempo- } \\
\text { rary Sociology, 6(2), } 197 . \\
\text { doi: } 10.2307 / 2065805\end{array}$ & $\begin{array}{l}\text { A flow experience occurs during situations in which people are } \\
\text { willing to invest psychic energy in tasks for which extrinsic } \\
\text { rewards are absent. Flow is described as a state of mind that is } \\
\text { spontaneous, almost automatic, like the flow of a strong current. } \\
\text { Intrinsic motivation (the interest component of this theory, which } \\
\text { is described as a state that combines positive affective and } \\
\text { cognitive qualities) is the main incentive for pursuing an activity } \\
\text { and, as such, interest must be present for a flow experience to } \\
\text { occur. Like intrinsic motivation, a flow experience requires no } \\
\text { external rewards. }\end{array}$ \\
\hline 2 & $\begin{array}{l}\text { John Dewey's view } \\
\text { on interest in } \\
\text { education }\end{array}$ & $\begin{array}{l}\text { Dewey, J. (1913). Interest and effort } \\
\text { in education. Whitefish, MT: } \\
\text { Kessinger Publishing. } \\
\text { doi:10.1037/14633-000 }\end{array}$ & $\begin{array}{l}\text { Dewey's theory of interest explains how interest might manifest } \\
\text { itself and interact in an educational environment. According to } \\
\text { Dewey, interest can be three things. First, interest can be an } \\
\text { action or propulsion toward engagement with content. For } \\
\text { example, an individual can take an interest in something. To be } \\
\text { interested in any matter is to be actively concerned with it. } \\
\text { Second, interest is objective. Interests are things that an } \\
\text { individual looks after. We identify interests with concerns or } \\
\text { affairs. Third, interest is personal; it signifies a direct concern; a } \\
\text { recognition of something at stake, something whose outcome is } \\
\text { important for the individual. It has its emotional as well as its } \\
\text { active and objective sides. Securing interest in facts or ideas is } \\
\text { essential for students to direct their energies toward mastering } \\
\text { those facts or ideas. }\end{array}$ \\
\hline
\end{tabular}

\section{Slightly More Than One-Third of Papers Referenced Theories Relating to Interest}

Fifty-one articles (37\%) mentioned a theory concerning interest or motivation (Table 2). Some sources cited and mentioned theories of interest or motivation but did not define interest as a component of that theory or elaborate on the meaning of interest for the study under investigation. We recorded each instance when a theory was cited or mentioned, not whether that theory was actually applied as a framework for the study, because it was often difficult to tell whether (or not) the theory was actually applied. As with the definitions of interest, many of the papers analyzed mentioned more than one theory relating to interest. Table 4 lists commonly referenced theories and includes a foundational publication (a publication that describes the referenced theory in detail and was published early and cited frequently in the history of the theory) and a brief description of each theory. Despite our choice of foundational publications, theories often represent a culmination of evidence and publication from several contributing authors. Publications referencing theory and the papers they cite are listed in Supplemental Table 2.

\section{A Majority of Papers Systematically Measured Interest, and There Are Multiple and Diverse Ways That Interest Was Measured}

Ninety-three articles (67\%) applied a systematic form of interest measurement (Tables 2 and 5). The majority of papers analyzed (53\% of measures papers) collected quantitative data using questionnaires including multiple-choice or Likert-type questions. Some of the papers applying systematic measurement collected qualitative data (24\%) using open-ended survey questions, interviews, observations, or student artifacts to assess student interest. Likewise, some papers used mixed methods to collect both qualitative and quantitative data (24\%; Table 5). Of the papers that used quantitative questionnaires, most were written by authors (67\%) who developed their own measurement items (Table 5), while others (38\%) used previously published questionnaires. There were occasions when authors used two scales to assess interest, including an existing, published questionnaire and one they developed, so the last two rows in Table 5 sum to more than 100\%.

We further characterized papers collecting quantitative data by inductively grouping them based on similarities in the measurement approach used (Table 6). Although measures of interest varied greatly overall, we were able to categorize all measures into five categories based on how the questionnaire items were assembled.

Before describing these categories, we define the terms used for the categories to clarify our descriptions. An "item" is a single question to which a respondent provides an answer. For example, "Biology classes are fun for me" with a Likert-type response scale constitutes a single item. A "dimension" is an underlying feature or component of a psychological construct,

TABLE 5. Type and origin of measurements used to assess interest in biology

\begin{tabular}{lc}
\hline Criterion & Number (\%) \\
\hline Papers that measured interest (of 138) & $93(67)$ \\
Papers collecting qualitative data (of 93) & $22(24)$ \\
Papers collecting quantitative data (of 93) & $49(53)$ \\
Papers collecting both qualitative and quantitative & $22(24)$ \\
$\quad$ data (of 93) & \\
Papers using existing published measures (of 71) & $27(38)$ \\
Papers developing their own measures (of 71) & $48(67)$ \\
\hline
\end{tabular}


TABLE 6. Measurement structures used to assess interest in biology

\begin{tabular}{|c|c|c|c|}
\hline $\begin{array}{l}\text { Type of interest } \\
\text { measurement }\end{array}$ & $\begin{array}{c}\text { Description of interest } \\
\text { measurement }\end{array}$ & $\begin{array}{l}\text { No. of papers } \\
\text { using }\end{array}$ & Examples of items or scales from each measurement type \\
\hline Single item & $\begin{array}{l}\text { Single items were used to probe } \\
\text { student interest. Reports of } \\
\text { interest were based on only one } \\
\text { item. }\end{array}$ & 25 & $\begin{array}{l}\text { To carry out experiments with plants (e.g., on factors affecting } \\
\text { germination and growth) is interesting for me. } \\
\text { Response options: } 0 \text { = disagree, } 1 \text { = partially agree, } 2 \text { = mostly agree, } \\
3=\text { agree. }{ }^{\text {a }} \\
\text { What do you think about planting and sowing seeds? (Circle what } \\
\text { you agree with most) } \\
\text { Response options: Very enjoyable, Quite enjoyable, Boring, Very } \\
\text { boring. } \text {. }^{\text {. }}\end{array}$ \\
\hline Single aspect & $\begin{array}{l}\text { Questionnaires used multiple items } \\
\text { to measure a single aspect of } \\
\text { interest. Reports of interest were } \\
\text { based on a sum or average of } \\
\text { these items. }\end{array}$ & 21 & $\begin{array}{l}\text { How interested are you in devoting time and effort to studying and } \\
\text { learning more about each of the skills listed below? } \\
\text { - The role of energy and equilibrium in cellular reactions } \\
\text { - Posttranslational mechanisms that regulate the function and } \\
\text { degradation of proteins } \\
\text { - } 9 \text { more items together interpreted as interest in cell biology } \\
\text { topics } \\
\text { Response options: } 0=\text { Not at all interested, } 1=\text { Only slightly } \\
\text { interested, } 2=\text { Fairly interested, } 3=\text { Quite interested, } \\
4=\text { Extremely interested. }\end{array}$ \\
\hline Multi-aspect & $\begin{array}{l}\text { Questionnaires using multiple items } \\
\text { that addressed different aspects } \\
\text { of interest. For example, items } \\
\text { could address affect, value, and } \\
\text { whether students would like to } \\
\text { learn a topic, or more diverse } \\
\text { aspects such as anxiety, interest, } \\
\text { curiosity, and behavior. Reports } \\
\text { of interest were based on a sum } \\
\text { or average of these disparate } \\
\text { items. }\end{array}$ & 19 & $\begin{array}{l}\text { - Biology classes are a lot of fun for me. } \\
\text { - I am tense during biology classes. } \\
\text { - I always learn interesting information during biology classes. } \\
\text { - I would like to be a biology teacher in the future. } \\
\text { Response options: } 1 \text { (strongly disagree) to } 5 \text { (strongly agree). }{ }^{\mathrm{d}}\end{array}$ \\
\hline Unknown & $\begin{array}{l}\text { Reviewed papers did not provide } \\
\text { enough information to classify } \\
\text { the questionnaire. }\end{array}$ & 7 & - \\
\hline
\end{tabular}

aHolstermann et al., 2010.

bNyberg and Sanders, 2014.

cKitchen et al., 2007.

${ }^{d}$ Kubiatko et al., 2017.

eLinnenbrink-Garcia et al., 2010; Heddy and Sinatra, 2017.

such as interest. A questionnaire measuring one underlying dimension is called a unidimensional scale, and a questionnaire measuring several distinctly different underlying dimensions is called a multidimensional scale. For example, "feelings-related valences" is considered to be one of three dimensions in Schiefele's (1991) conceptualization of interest (see Table 4). Importantly, when interpreting a number of items as representing similar or separate dimensions, one must test them using psychometric testing methods such as exploratory factor analysis. We used the term "aspects" as a nonstatistical term simply describing whether a scale theoretically included items repre- senting one (single aspect) or several (multi-aspect) components of interest. Thus, the term "aspect" is nearly synonymous with "dimension," except that it has no statistical meaning. Just like a dimension, an aspect is not delineated by biology topic or subtopic, but rather by the psychological feature that is addressed (e.g., positive affect, knowledge, or value). We use these terms in our categorization of measures.

The most frequent type of measures used were single-item measures, wherein one item was used to probe students' interest (Table 6, see single item). In some cases, there were multiple single-item measures in one questionnaire. If the authors did 
TABLE 7. Common measurement aspects assessed by single-item and single-aspect scales

\begin{tabular}{lc}
$\begin{array}{l}\text { Type of interest } \\
\text { measurement }\end{array}$ & \multicolumn{1}{c}{$\begin{array}{c}\text { Description of } \\
\text { interest measurement }\end{array}$} \\
\hline Interest focused & $\begin{array}{c}\text { Questionnaires exclusively using the word "interest" } \\
\text { or "interesting" when asking about student's } \\
\text { interest. Typically, these scales were used to } \\
\text { probe students' interest for certain activities or } \\
\text { topics. }\end{array}$ \\
& $\begin{array}{l}\text { Questionnaires that included only affect-related } \\
\text { items (i.e., feeling, liking, enjoyment, boredom) } \\
\text { and occasionally included items using the word } \\
\text { "interest," which could not be separated from } \\
\text { affect, given the scale. }\end{array}$ \\
& $\begin{array}{c}\text { Instances in which items asked students whether } \\
\text { they wanted to learn a topic or whether it } \\
\text { Whould be taught in science. These scales are } \\
\text { then interpreted as interest. }\end{array}$
\end{tabular}

No. of papers using

24

How interesting do you find object A?
Response options: 1 (lowest) to 5 (highest).

10

How do you feel about watching a caterpillar turn into a butterfly?

Response options: 5 = It's awesome, $4=$ It's cool, $3=$ It's okay, 2 = It's not cool, 1 = It's boring. ${ }^{\text {b }}$

12 How interested are you in learning about the following?

1. Animals in other parts of the world

2. Dinosaurs, how they lived and why they died out

Response options: 1 (strongly disagree) to 5 (strongly agree). ${ }^{c}$

aStrgar, 2007.

'Paris et al., 1998.

'Schreiner and Sjøberg, 2004. Referenced by three papers in our review.

not combine these items into a sum score, but instead reported results from each item separately, the measures were still characterized as single item. For example, if authors asked multiple questions about interest in different topics (e.g., interest in anatomy and interest in biochemistry) but did not combine these responses into a single sum score (i.e., overall interest in biology), then the questionnaire was characterized as "single item."

Single-aspect measures were common. Single-aspect measures used multiple items to explore one aspect of interest, such as affect or value (see Table 6, single aspect). Unlike single-item measures, single-aspect measures use the combined scores of multiple items to create a sum score or mean score. Singleaspect measures also included instances when researchers asked questions about interest in different biology topics and summed the responses to indicate interest in a broader topic.

Another common strategy was to use a mix of items that asked about a variety of interest aspects and sum or average them to represent interest (see Table 6, multi-aspect). In many cases, these items were assembled without a clear underlying rationale for why they could be combined (i.e., theory was not used to inform the assembly and/or psychometric testing was absent). Taken together, the mix of items in these measures was treated like a latent variable measuring interest broadly.

A less common strategy was to use multiple items that draw on theory or previous findings to specifically measure different dimensions of interest (see Table 6, multidimensional scales). For example, separate sets of items targeting affect, values, and behavior might be measured. The items measuring each separate dimension could then be summed or averaged to provide a separate value for each dimension. Finally, researchers could look across these three scores to draw conclusions about the general construct of "interest." This type of measurement, which seeks to ask questions related to various component parts (i.e., dimensions) of a construct, is a considered a best practice among psychometricians (Bandalos, 2018).

It is important for us to note that some of the papers that measured interest reported it as one component of another larger construct, such as motivation. These papers included sub- scales to measure interest, which we then categorized into one of the four main categories (Table 6). Although these papers might be multidimensional overall, in their measure of interest, they might fall into single aspect, single item, or multi-aspect.

We further classified the single-item and single-aspect measures based on the aspect of interest measured. The most frequently employed single-item or single-aspect measures used only the word "interest" in their items, which relies on the participants' own definitions and understandings of interest when answering the question (see Table 7, interest-focused). Many other single-item and single-aspect measures asked only about students' affect, such as liking, enjoyment, boredom, and so on (see Table 7, affect only). A third, less frequent category of measures asked about topics that students wanted to learn more about or topics they felt should be taught (see Table 7, want to learn). Overall, our categorization highlights the wide variation in the way interest is measured and the aspects commonly considered to be part of interest. Supplemental Table 3 lists the papers that measured interest and the measurement approaches they used.

\section{Two Broad Themes Emerged from Analysis of the Literature across Categories}

First, interest was always described in relation to an object within the analyzed set of biology education research papers. An "object" for our purposes is defined as an external entity toward which a specific action or feeling can be directed and can include a physical object, activity, or topic. All common definitions referred to an object (Table 3). Two cited definitions referred to an "object" specifically (Schiefele, 1991; Hidi and Renninger, 2006), while others referred to an activity (Gardner and Tamir, 1989; Ryan and Deci, 2000) or external stimuli (Csikszentmihalyi and Hemanson, 1995). This pattern was echoed in the analyzed measures in which an "object" (e.g., biology, one's major, pea plants, an assignment) was always related to a student's interest. Notably, all of the theories referenced in Table 4 also refer to "objects" using terms such as "class of content" (Hidi and Renninger, 2006), "object” (Schiefele, 1991; Krapp, 1993), 
or "activities" and "tasks" (Davis and Csikszentmihalyi, 1977; Wigfield and Eccles, 2000). We can conclude that the biology education research community largely views interest as connected to a specific external entity, such as the topic or study of biology. This is in contrast to viewing interest as a disposition of an individual that is applied regardless of external stimuli (i.e., one is simply "interested" as description of one's character).

Second, positive affect associated with the object of interest is a broad theme. All five commonly referenced definitions of interest referred to affect as a component of interest and reference positive affect using terms such as "preference" (e.g., Gardner and Tamir, 1989; Hidi and Renninger, 2006) and "enjoyment" (e.g., Csikszentmihalyi and Hemanson, 1995; Ryan and Deci, 2000). Positive affect was also the sole subject of 10 measures (Table 7), and items that assess positive affect associated with an object are consistently present in multi-aspect and multidimensional scales (e.g., "I find working on biology assignments very fun," "Being in a biology major puts me in a good mood"; Table 6 and Supplemental Table 3). Similarly, all commonly referenced theories referred to positive affect as a component of interest (Table 4). Considering these results, it is clear that biology education researchers consistently view positive affect directed toward an object as an aspect constituting at least part (if not all) of interest.

\section{DISCUSSION}

In this work, we aimed to investigate how students' interest in biology has been defined and measured and whether previously published work investigating students' biology interest draws from theories of interest or motivation. The analysis and the synthesis that follows reveals what researchers have considered when reporting on interest in biology education contexts and helps us to better interpret results regarding interest in these contexts. This analysis also highlights how we, as a field, can move forward and further develop the generalizability, utility, and depth of our research on interest within biology education.

\section{Conclusion 1: Interest Was Not Often Defined, but When Interest Was Defined, Definitions Were Based on a Range of Published Theories}

When investigating any construct, it is recommended that one clearly express how the construct is defined (American Educational Research Association [AERA], American Psychological Association [APA], and National Council on Measurement in Education [NCME], 2014). As mentioned in the Introduction and seen in the Results (Table 3), interest can be defined in many different ways. There is no one accepted or "right" definition of interest. For example, Wigfield and Eccles (2000) define interest as doing something because it is inherently enjoyable, while Hidi and Renninger (2006) and Schiefele (1991) include more dimensions in their definitions, such as experiencing positive affect, holding value for a topic, and being predisposed to reengage. Because there are multiple ways to define interest, presenting a clear definition is important, as the results and interpretation of studies will differ depending on the construct's definition and measurement (Figure 1). The absence of a definition makes it challenging to select appropriate methods to investigate the construct and to compare one's results with other studies.
In our analysis, studies that presented a definition of interest (26\% of all studies) drew definitions from published theories originating in the fields of psychology and education (Table 4). This aligns with calls for use of theory to ground studies in biology education research (Dolan, 2015). However, the majority of studies $(74 \%)$ did not present a definition of interest in the introduction or methods (Table 2). Furthermore, 24 (34\%) of the quantitative measures used the word "interest" in measurement items without providing a definition of interest to respondents (Table 7). For example, a question may have asked "How interested are you in biology?" or offered Likert-type response options that ranged from "Not at all interested" to "Very interested." The absence of definitions in these two locations is problematic, because it is likely that different people hold slightly different ideas about what the word "interest" means (Krapp, 2002). Lacking a definition in the introduction and methods sections creates ambiguity for readers, allowing them to apply their own definitions of interest to the research, which may not align with that of the paper's author. For instance, if a reader interprets a reported increase in interest as a lasting desire to reengage with a topic, but the author intended only to express that students "enjoyed" the introduced activity, the reader might overextend the results to conclude that that activity is more impactful than it actually is. In the case of interest measures, researchers are relying on participants' own interpretation of the word "interest" to inform their responses, which could result in different respondents applying different understandings of the term "interest" to inform their responses. Indeed, different interpretations of what interest means may unintentionally introduce bias into a study and consequently make results difficult to interpret. This can be avoided, however, if the author defines interest and makes his or her understanding transparent when choosing measures and reporting results.

\section{Conclusion 2: Theoretical Frameworks Were Not Often Described, but among Papers That Described a Theory, the Theories Referenced Varied}

The biology education research community has called for increased use of theory in education research and integration of biology education research with other fields such as cognitive science and social psychology (Dolan, 2015). Use of theory in research enables a researcher to 1) position their research questions within an existing, vetted framework; 2) justify the importance and significance of their research; and 3) ground the research results in a larger body of prior work, which allows comparisons to be made between current and previous studies (Creswell, 2014). While detailed descriptions of the theory that informs the research are often not necessary, a brief reference to a guiding theory can help readers to interpret the results in the way the author intended. Owing to the variation in interest conceptualizations, use of theory can quickly and efficiently clarify how interest is being discussed and situated within a research context.

Thirty-seven percent of papers analyzed referenced theory with respect to interest. Among these papers, seven different theories were commonly referenced (Table 4), leading us to conclude that a variety of theoretical frameworks can be used to understand interest in biology education contexts. The most commonly referenced theories and definitions draw from the 
work of Hidi and Renninger (2006), authors of the four-phase model of interest development; Krapp (1993), author of the person-object theory of interest; and Ryan and Deci (2000), authors of self-determination theory (Table 4). Eighty-eight percent of papers that referenced theory referred to at least one of these theories (Supplemental Table 2). All of these theories draw upon multiple dimensions to describe interest and how it affects an individual's thoughts and behavior. Furthermore, both the four-phase model and self-determination theory focus on how interest develops over time. These findings suggest that biology education researchers who reference theory most often use multidimensional and developmental theories to ground their work. This is not surprising, because developmental theories lend themselves to studies aimed at enhancing students' interest in an academic topic. Papers that reference these theories provide a starting point for researchers wanting to explore interest as developmental, multifaceted, and behavioral.

The results from papers referencing theory are informative; yet overall, few papers referenced theory (37\%; Table 2$)$. While this is not always problematic, because interest could be described without using theory (i.e., providing a definition or describing the researcher's own idea of interest), it represents a missed opportunity to relate the results of a study to prior work and knowledge. Furthermore, papers lacking both an interest definition and theoretical grounding present a challenge to accurate interpretation for the reasons described in the previous section. As such, the call for integration of theory into biology education research (Dolan, 2015) is pertinent, especially in the case of interest.

\section{Conclusion 3: The Methods Used to Measure Interest Varied Greatly and Often Consisted of One Item or Measured Only One Aspect of Interest}

Understanding how a psychological construct, such as interest, has been measured is essential for accurately interpreting the results, claims, and implications of a research study (Bandalos, 2018). Measurement should be tailored to address the research questions asked, the theory or definitions drawn upon, and the context of the study (AERA, APA, and NCME, 2014; Knekta et al., 2019). Ninety-three studies (67\% of all studies analyzed) measured interest systematically, and of those, 71 studies used quantitative questionnaires that we could classify into measurement types (Tables 6 and 7). Questionnaire structures and items varied greatly. Much of this variation can be explained by differences in the theories and definitions driving each study, but another portion of variation is likely due to lack of knowledge and use of measurement best practices.

The choice of different conceptualizations, definitions, or theories across studies often results in the use of different items and questionnaire structures. This variation in measurement does not necessarily constitute a limitation to the interpretation of any one paper as long as that paper is grounded in a clear conceptualization of interest. However, the broad variation we observed in interest measurement means that careful consideration is needed when comparing results across studies. Single-aspect scales that measure positive affect can illustrate why care should be taken. Ten analyzed studies probed only students' positive affect, such as their "enjoyment" or "liking," when measuring interest (Table 7). Some theories of interest, such as expectancy-value theory (Wigfield and Eccles, 2000), view positive affect as the sole dimension that constitutes interest. For papers drawing on these theories, it is appropriate to use a measure that only addresses positive affect. However, according to other theories, positive affect is only one dimension of interest; interest is also cognitive, behavioral, and related to one's values (e.g., the four-phase model [Hidi and Renninger, 2006], valence beliefs [Schiefele, 1991], flow [Dewey, 1913; Davis and Csikszentmihalyi, 1977]). The four-phase model of interest development even recognizes that negative affect may be at play in early stages of interest development (Ainley and Hidi, 2014). Thus, a reader needs to understand how the author conceptualizes interest before drawing conclusions. For example, it would be a mistake for a reader to apply theories that view interest as multidimensional to interpret papers measuring only positive affect. Additionally, as a researcher, it would be a mistake to reference a theory that conceptualizes interest as multidimensional, but only measure positive affect. Perhaps most importantly, comparison of studies that use different frameworks to define and measure interest is not appropriate when interest conceptualizations differ. The take-home message is that a study's purpose and theory should drive the choice of measures used, and readers should strive to understand how different studies conceptualized and measured interest before making cross-study comparisons.

While measuring a single aspect of interest is not necessarily a bad practice, we observed two other measurement structures that did not follow psychometric best practices. The first was the use of a single item to represent the construct of interest. Interest is not directly observable (unlike height, monthly salary, or percent of international students in a class). Therefore, interest cannot be measured directly using a single item (Knekta et al., 2019). Instead, using students' scores from several items measuring interest in slightly different ways and combining them into a sum or mean score is preferred. For example, if interest is defined as positive affect in relation to an object, one could include a number of items asking students about positive affect in their measure, such as how enjoyable they found the task, whether they liked to do the task, and how happy they were while completing the task. Students' answers on these questions would be combined to represent interest as a whole, a common best practice in measuring psychological constructs (Knekta et al., 2019).

The second questionable measurement structure involved the combination of items representing multiple aspects of interest into one sum or mean score, often without theoretical and/ or empirical grounding (such scales were classified as "multi-aspect"; see Table 6). A foundational assumption in measurement theory is that the psychological construct in question, in this case interest, is what drives respondents to answer similarly on all items that one intends to combine into a sum or mean score. In the case of many multi-aspect measures, this assumption is not established theoretically or empirically. For example, one study asked students to rate their agreement with the following statements as part of an interest scale: "I had fun while handling the laboratory instruments," "Doing experiments helped me to understand the topic better," and "Conducting the experiments increased my interest in the topic" (Glowinski and Bayrhuber, 2011). It is easy to imagine a student who did not enjoy handling lab equipment (first item) but did find the experiment interesting (third item). These differences in question responses 
indicate that additional constructs, other than interest, or different aspects of interest are represented in these items. This makes the sum score challenging to interpret at best and meaningless at worst (for a detailed explanation, see Knekta et al., 2019). Similarly, if the theory of interest being used is multidimensional, one would not want to sum across dimensions, because they represent different aspects of interest and students may respond to them differently. Thus, multi-aspect measures should be avoided or theoretical and empirical evidence that the items can be summed should be provided.

\section{Conclusion 4: The Biology Education Community Largely Views Interest as a Person-Object Relationship and Affect Focused}

Despite the broad variation across these studies, we can still glean information from themes present in the literature that did define, measure, or use theory to explore interest. These themes provide insights into how the broader biology education research community conceptualizes interest. The first theme identified a person-object relationship as a critical characteristic of interest in biology education contexts. Researchers consistently refer to interest as describing the relationship between a person and a specific "object," such as a topic of study (i.e., biology), an activity, or other external stimuli. These results indicate that the community generally does not view interest as a stable disposition of the student that could relate to any content area (i.e., a student is not inherently "interested" in general; instead they are "interested" in something specific). This view is consistent with interest theories that are both referenced (e.g., Davis and Csikszentmihalyi, 1977; Schiefele, 1991; Krapp, 1993; Ryan and Deci, 2000; Wigfield and Eccles, 2000; Hidi and Renninger, 2006) and not referenced (e.g., social cognitive career theory; Lent et al., 2002) within the analyzed literature. This finding highlights the view that interest is context dependent and implies that development of a specific biology or STEM interest could be an outcome in educational environments.

A second theme present throughout the literature is the centrality of positive affect in the research on interest in biology contexts. Both studies that included theory and those that did not expressed the view that positive affect is an aspect of interest via either their definition or measurement of interest. Positive affect in connection with interest was expressed using words and phrases such as "enjoyment," "liking," "fun," and "good mood." Again, this is consistent with many interest theories, which view positive affect as an indication of interest (Davis and Csikszentmihalyi, 1977; Schiefele, 1991; Krapp, 1993; Ryan and Deci, 2000; Wigfield and Eccles, 2000; Lent et al., 2002; Hidi and Renninger, 2006). However, much of the analyzed literature described positive affect as the sole dimension constituting interest, while a majority of theories recognize and describe how other dimensions contribute to interest (e.g., stored value; Schiefele, 1991). Uncovering this conceptualization is helpful, because it can be used to better understand past studies, frame future work, and lend clarity to our understanding of interest within the biology education research literature.

\section{Next Steps}

In earlier sections, we discussed both limitations and insights gleaned from the current body of biology education research. Despite the limitations discussed, we recognize the invaluable contribution of the many papers analyzed in this work. All analyzed papers have contributed to our understanding of how biology interest develops in educational settings and how it contributes to students' engagement among other topics. While we feel that there is room for growth in future work on interest, the current literature has taken important steps in exploring and defining this construct within the context of biology education. With this in mind, we make three recommendations to authors of future work on interest in biology learning contexts.

\section{We advocate for clarity in interest definitions.}

Clear definitions will allow future researchers to accurately describe what they seek to study and measure, which will lead to clarity in both measurement and interpretation of results. We urge researchers to draw from prior work to define interest and to use these definitions at four strategic points in their work:

a. A definition should be agreed upon by all researchers at the start of the project and revisited to ensure construct fidelity throughout the study.

b. Researchers should confirm alignment between the definition of interest and the method selected to measure it (i.e., that the items on a questionnaire represent the aims of measurement).

c. If questionnaires or interview prompts use the term "interest," the term should be defined in the measure before the question to help study participants use the conception of interest the researcher intended rather than one they may already hold.

d. A definition should be included in all reports of results from interest studies.

These four uses of a definition can help clarify what is meant by results regarding student interest and how results relate to prior work.

2. We advocate for the use of theory to ground studies of interest in biology education contexts.

Thoroughly understanding interest, which is necessary for choosing items or writing a definition, can be achieved through knowing how it functions as a component of common theories. Biology education researchers may find the following uses of theory helpful:

\section{a. Define a construct.}

Theory can generate a broadly applied definition of interest for use in research. Even when a study does not seek to inform theory or explore a theory's application to a certain context, theories can help researchers to define interest, which grounds the research in vetted descriptions of the construct.

\section{b. Test new contexts.}

Researchers can test theories in different educational contexts. Theories are meant to guide hypotheses and explain general patterns, but they may not apply to all situations. Understanding when theories do and do not apply is useful for understanding the roles of interest in educational settings.

c. Ground and compare results.

Researchers can use a guiding theory to ground their research in prior work and relate their results to other studies. 
For example, if two researchers are using the same theory, they can compare their findings regarding how interest fits into frameworks used to understand motivation or interest development.

\section{d. Extend future work.}

Researchers can use theories to extend their work and generate future directions. For example, a theory might suggest different mediators or moderators of interest that could be measured to more fully understand an educational system.

3. We advocate for a careful selection of measures and cautious comparison of results.

The quality of the results and conclusions from a study is inherently dependent on the method and measures used to collect data. The validity-simply defined as the ability of a measure to accurately measure what it purports to measure-of any measure is specific to the research question being asked and the context in which it is asked. Thus, if a measure is invalid for the context in question, then the inferences drawn from its use are also not valid. We strongly recommend using existing interest measures and providing information on the degree to which evidence and theory support the interpretations of the scores for the context in question (for examples, see Creswell, 2014, p. 201; AERA, APA, and NCME, 2014, pp. 11-22). A starting point for this could be papers listed in Supplemental Table 3 in the "use existing questionnaire" category. Also, we recommend that authors who seek to compare their results with others' results first consider how interest was measured by the other researchers. Making broad comparisons across the literature without first considering the nuances of interest measurement could lead to inaccurate and confusing results. After all, measuring interest can mean so many different things.

\section{CONCLUSION}

The diversity of definitions, measures, and theories that address interest are a benefit to biology education researchers, because researchers can choose among many available options to find those most applicable to their research context. However, choosing among interest measures or theories and finding other literature that uses similar frameworks can be daunting. To help readers of this paper navigate the biology education research that examines interest, we have included three supplemental Excel tables describing our work (Supplemental Tables 1-3). The first table consists of papers that define interest and lists publications they cite for their definitions. The second table lists papers that cite theories and lists the papers that were cited in reference to the theory. The third table lists papers that measured interest and describes the origin and categorization of each measure. Each table is presented as a matrix of ones and zeros and can be sorted using Microsoft Excel or other programs to view which theories, definitions, and types of measures various publications used and which publications have definitions, theories, or measures in common. We hope that these supplemental tables are useful for readers who would like to explore biology education research related to interest.

In closing, we urge biology education researchers studying interest to carefully consider this construct and its measurement. While we recognize that it may not always be practical to include lengthy measures or discussions of theory in every publication, defining the term "interest" for readers and study participants can go a long way toward alleviating ambiguities and adding clarity and utility to a study. Building students' interest in biology has implications for their persistence in biology classes and beyond. We hope that this analysis will contribute to future research on students' biology interest and, ultimately, further the goal of increasing biology graduates' enthusiasm for the field.

\section{ACKNOWLEDGMENTS}

We are grateful for useful input on this article by Dr. Jennifer Avena and Dr. Betsy McIntosh. This material is based on work supported by the National Science Foundation under grant no. 1615143.

\section{REFERENCES}

Ainley, M., \& Hidi, S. (2014). Interest and enjoyment. In Pekrun, R., \& Linnenbrink-Garcia, L. (Eds.), International handbook of emotions in education (205-227). New York: Routledge. doi: 10.4324/9780203148211 ch11

American Educational Research Association, American Psychological Association, \& National Council on Measurement in Education. (2014) Standards for educational and psychological testing. Washington, DC: American Educational Research Association.

Bandalos, D. L. (2018). Measurement theory and applications for the social sciences (1st ed.). New York: Guilford

Cacciotti, G. (2015). Fear of failure in entrepreneurship: A review, conceptualization and operationalization. Coventry, England: University of Warwick.

Creswell, J. W. (2014). Research design: Qualitative, quantitative, and mixed methods approaches (4th ed.). Thousand Oaks, CA: Sage.

Csikszentmihalyi, M., \& Hemanson, K. (1995). Intrinsic motivation in museums: Why does one want to learn? Public Institutions for Personal Learning 74(34), 67-75.

Davis, M. S., \& Csikszentmihalyi, M. (1977). Beyond boredom and anxiety: The experience of play in work and games. Contemporary Sociology, 6(2), 197. doi: $10.2307 / 2065805$

Dewey, J. (1913). Interest and effort in education. Whitefish, MT: Kessinger Publishing. doi: 10.1037/14633-000

Dolan, E. L. (2015). Biology education research 2.0. CBE-Life Sciences Education, 14(4), ed1. doi: 10.1187/cbe.15-11-0229

Dunkerton, J. (2007). Biology outside the classroom: The SNAB visit/issue report. Journal of Biological Education, 41(3), 102-106. doi: 10.1080/ 00219266.2007.9656077

Eccles, J. S., Fredricks, J. A., \& Epstein, A. (2015). Understanding well-developed interests and activity commitment. In Renninger, K. A., Nieswandt M., \& Hidi, S. (Eds.), Interest in mathematics and science learning (pp. 315330). Washington, DC: American Educational Research Association. doi: 10.3102/978-0-935302-42-4_18

Gardner, P. L., \& Tamir, P. (1989). Interest in biology. Part I: A multidimensional construct. Journal of Research in Science Teaching, 26(5), 409-423. doi: 10.1002/tea.3660260506

Glowinski, I., \& Bayrhuber, H. (2011). Student labs on a university campus as a type of out-of-school learning environment: Assessing the potential to promote students' interest in science. International Journal of Environmental and Science Education, 6(4), 371-392.

Glynn, S. M., Bryan, R. R., Brickman, P., \& Armstrong, N. (2015). Intrinsic motivation, self-efficacy, and interest in science. In Renninger, K. A., Nieswandt, M., \& Hidi, S. (Eds.), Interest in mathematics and science learning (pp. 189-202). Washington, DC: American Educational Research Association.

Graham, M. J., Frederick, J., Byars-Winston, A., Hunter, A.-B., \& Handelsman J. (2013). Increasing persistence of college students in STEM. Science 341(6153), 1455-1456. doi: 10.1126/science.1240487

Hansen, J. C., Sullivan, B. A., \& Luciana, M. (2011). A social neuroscientific model of vocational behavior. Journal of Career Assessment, 19(3), 216 227. doi: $10.1177 / 1069072710395529$

Heddy, B. C., \& Sinatra, G. M. (2017). Transformative parents: Facilitating transformative experiences and interest with a parent involvement intervention. Science Education, 101(5), 765-786. doi: 10.1002/sce.21292 
Hidi, S. (1990). Interest and its contribution as a mental resource for learning. Review of Educational Research, 60(4), 549-571. doi: 10.3102/ 00346543060004549

Hidi, S., \& Baird, W. (1986). Interestingness-A neglected variable in discourse processing. Cognitive Science, 10(2), 179-194. doi: 10.1016/S0364 -0213(86)80003-9

Hidi, S., \& Renninger, K. A. (2006). The four-phase model of interest development. Educational Psychologist, 41(2), 111-127. doi: 10.1207/ s15326985ep4102_4

Holstermann, N., Grube, D., \& Bögeholz, S. (2010). Hands-on activities and their influence on students' interest. Research in Science Education 40(5), 743-757. doi: 10.1007/s11165-009-9142-0

Kitchen, E., Reeve, S., Bell, J. D., Sudweeks, R. R., \& Bradshaw, W. S. (2007) The development and application of affective assessment in an upper-level cell biology course. Journal of Research in Science Teaching, 44(8), 1057-1087. doi: 10.1002/tea.20188

Knekta, E., Runyon, C., \& Eddy, S. (2019). One size doesn't fit all: Using factor analysis to gather validity evidence when using surveys in your research. CBE-Life Sciences Education, 18(1), rm1. doi: 10.1187/cbe.18-04-0064

Krapp, A. (1993). Characteristics of individual interests and interest-related actions from the perspective of a person-object theory. Studies in Educational Psychology, 4(January), 297-329. doi: 10.17559/TV-20150807194942

Krapp, A. (2002). 18 : An educational-psychological theory of interest and its relation to SDT interest: A rediscovered motivational concept. In Deci, E. L., \& Ryan, R. M. (Eds.), Handbook of self-determination research (pp. 405-426). Rochester, NY: University of Rochester Press.

Kubiatko, M., Torkar, G., \& Rovnanova, L. (2017). The teacher as one of the factors influencing students' perception of biology as a school subject. Center for Educational Policy Studies Journal, 7(2), 127-140. doi: 0111-pedocs-146000

Lent, R. W., Brown, S. D., \& Hackett, G. (2002). Social cognitive career theory. In Brown, D. (Ed.), Career choice and development (pp. 255-311). San Francisco, CA: Jossey-Bass.

Linnenbrink-Garcia, L., Durik, A. M., Conley, A. M., Barron, K. E., Tauer, J. M. Karabenick, S. A., \& Harackiewicz, J. M. (2010). Measuring situational interest in academic domains. Educational and Psychological Measurement, 70(4), 647-671. doi: 10.1177/0013164409355699

Nyberg, E., \& Sanders, D. (2014). Drawing attention to the "green side of life." Journal of Biological Education, 48(3), 142-153. doi: 10.1080/ 00219266.2013 .849282

Pacifici, L. B., \& Thomson, N. (2011). Undergraduate science research: A comparison of influences and experiences between premed and nonpremed students. CBE-Life Sciences Education, 10(2), 199-208. doi: 10.1187/cbe.11-01-0005

Paris, S. G., Yambor, K. M., \& Packard, B. W. (1998). Hands-on biology: A museum-school-university partnership for enhancing students' inter- est and learning in science. Elementary School Journal, 98(3), 267288.

Renninger, K. A. (2000). Individual interest and its implications for understanding intrinsic motivation. In Sansone, C., \& Harackiewica, J. M. (Eds.), Intrinsic and extrinsic motivation: The search for optimal motivation and performance (pp. 373-404). Amsterdam, Netherlands: Elsevier. doi: 10.1016/B978-012619070-0/50035-0

Renninger, K. A., \& Hidi, S. (2011). Revisiting the conceptualization, measurement, and generation of interest. Educational Psychologist, 46(3), 168184. doi: 10.1080/00461520.2011.587723

Renninger, K. A., \& Hidi, S. E. (2015). The power of interest for motivation and engagement. Abingdon, UK: Routledge. doi: 10.4324/9781315771045

Renninger, K. A., Nieswandt, M., \& Hidi, S. (Eds.) (2015). Interest in mathematics and science learning. Washington, DC: American Educational Research Association. doi: 10.3102/978-0-935302-42-4

Ryan, R. M., \& Deci, E. L. (2000). Self-determination theory and the facilitation of intrinsic motivation, social development, and well-being. American Psychologist, 55(1), 68-78. doi: 10.1037/0003-066X.55.1.68

Schiefele, U. (1991). Interest, learning, and motivation. Educational Psychol ogist, 26(3-4), 299-323. doi: 10.1080/00461520.1991.9653136

Schiefele, U., \& Csikszentmihalyi, M. (1994). Interest and the quality of experience in classrooms. European Journal of Psychology of Education, 9(3), 251-270.

Schiefele, U., Krapp, A., \& Winteler, A. (1992). Interest as a predictor of academic achievement: A meta-analysis of research. In Renninger, K. A. Hidi, S., \& Krapp, A. (Eds.), The role of interest in learning and development (pp. 183-212). Hillsdale, NJ: Erlbaum. Retrieved January 22, 2019 from http://opus.kobv.de/ubp/volltexte/2009/3352/pdf/schiefele1992 -8.pdf

Schreiner, C., \& Sjøberg, S. (2004). Sowing the seeds of ROSE. Background rationale, questionnaire development and data collection for the ROSE (The relevance of science education): A comparative study of students views of science and science education. Oslo, Norway: Acta Didactica, Department of Teacher Education and School Development, Faculty of Education, University of Oslo.

Seymour, E., \& Hewitt, N. (1997). Talking about leaving: Why undergraduates leave the sciences. Boulder, CO: Westview.

Strgar, J. (2007). Increasing the interest of students in plants. Journal of Biological Education, 42(1), 19-23. doi: 10.1080/00219266.2007.9656102

Thorndike, E. L. (1935). Adult interests. Oxford, UK: Macmillan.

Valsiner, J. (1992). Interest: A metatheoretical perspective. In Renninger, K. A., Hidi, S., \& Krapp, A. (Eds.), The role of interest in learning and development (pp. 27-41). Hillsdale, NJ: Erlbaum.

Wigfield, A., \& Eccles, J. S. (2000). Expectancy-value theory of achievement motivation. Contemporary Educational Psychology, 25(1), 68-81. doi: $10.1006 /$ ceps.1999.1015 